\title{
Abdominal wall hematoma related to severe cough in a patient under antiaggregant and anticoagulant therapy
}

\author{
Mehmet Fatih Ozlu • Suzi Selim Ayhan • \\ Serkan Öztürk · Alim Erdem • Mehmet Yazıcı
}

Received: 20 January 2012/Accepted: 21 March 2012/Published online: 1 April 2012

(C) SIMI 2012

\begin{abstract}
A 56-year-old woman with coronary artery disease presented with the complaint of chest pain. She was hospitalized with the diagnosis of acute coronary syndrome. She was taking acetylsalicylic acid, metoprolol, atorvastatin and isosorbide mononitrate for coronary artery disease. The medical history included: diabetes mellitus, hypertension, and coronary artery bypass grafting surgery. The blood pressure was $170 / 100 \mathrm{mmHg}$ and the heart rate was 94 beats/min. There was no significant finding on physical examination other than a mild systolic murmur at the apical region. Laboratory testing revealed the following values: glucose: $87 \mathrm{mg} / \mathrm{dL}$, troponin I: $3.07 \mathrm{ng} / \mathrm{mL}$, CK-MB: 18.3 U/L, hemoglobin: $8.6 \mathrm{~g} / \mathrm{dL}$, thrombocyte: $247,000 /$ $\mathrm{mm}^{3}$ and INR: 1.07 . Besides the existing treatment, nitroglycerine infusion, subcutaneous enoxoparine, clopidogrel, amlodipine and perindopril medication was started. On the third day of treatment, a non-productive severe cough started. It was thought to be related with the ACE inhibitor, or an upper respiratory tract infection. The ACE inhibitor medication was converted to an angiotensin receptor blocker. On the fourth day of hospitalization, severe abdominal pain and a painful right upper quadrant mass developed (Fig. 1). The hemoglobin level decreased to $8.1 \mathrm{~g} / \mathrm{dL}$. Two units of red blood cell suspension were transfused. Abdominal ultrasound examination revealed an abdominal hematoma. All of the anticoagulant and antiaggregant medications were stopped. Abdominal computed tomography was performed. A $13.4 \times 8.9 \mathrm{~cm}$ hematoma between the right internal oblique and external oblique
\end{abstract}

M. F. Ozlu ( $₫)$ · S. S. Ayhan · S. Öztürk · A. Erdem ·

M. Yazıc1

Department of Cardiology, Faculty of Medicine, Abant Izzet

Baysal University, 14280 Bolu, Turkey

e-mail: drmfo@yahoo.com muscles was detected (Fig. 2). Initially, the surgeons planed an operation to ligate the bleeding vessel under general anesthesia, but, because of the high risk of the patient due to the acute coronary syndrome, they suggested conservative non-operative management. Because of the patient's unbearable pain, percutaneous catheter placement and drainage had to be performed. Control USG revealed reduced diameters of the hematoma. The cough improved 5 days after the conversion to an angiotensin receptor blocker; this suggested that the cause of the cough was the ACE inhibitor rather than upper respiratory tract infection. The patient recovered and was discharged.

Cough is a vital reflex to clear airways for pulmonary clearing. Abdominal muscles suddenly contract to increase

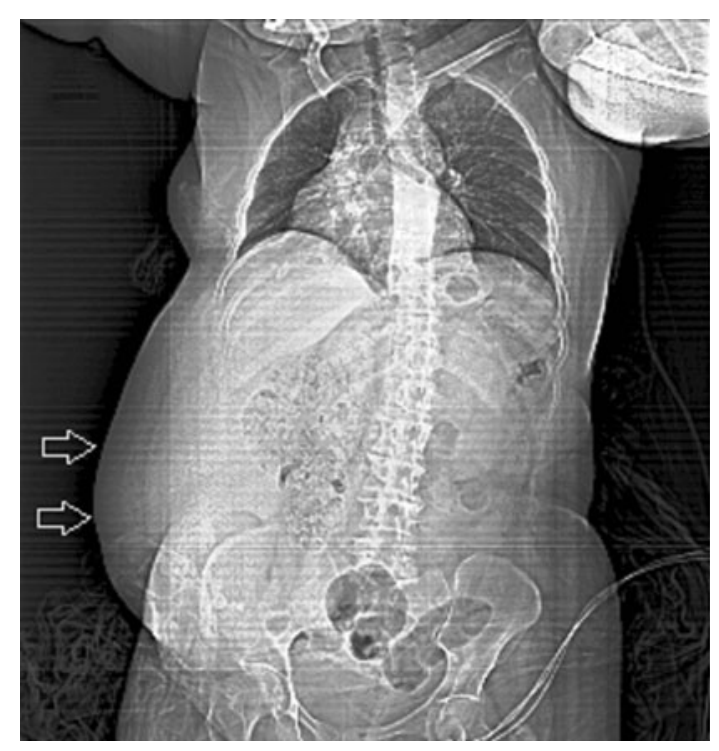

Fig. 1 Topogram of the abdominal computed tomography showing the swelling on right abdomen (arrows) 


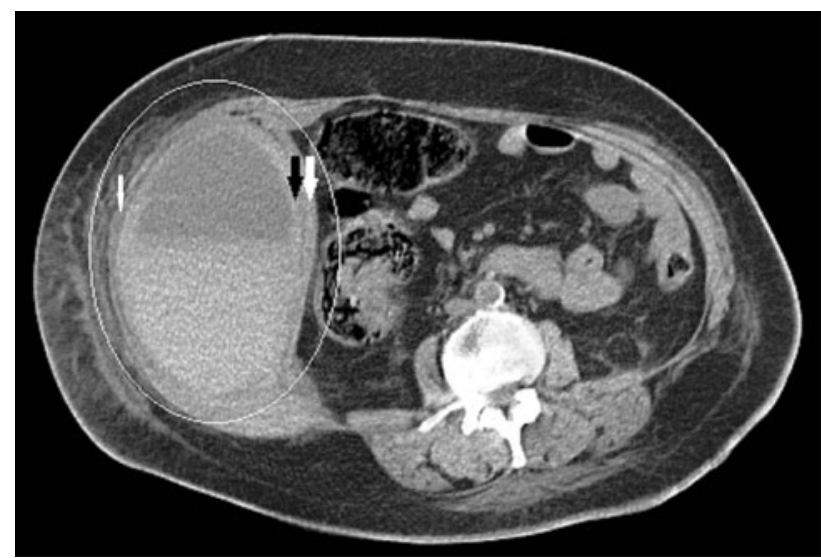

Fig. 2 Giant right abdominal wall hematoma (within the ellipse) between internal oblique (black arrow) and external oblique (thin white arrow) muscles shown in the abdominal computed tomography (thick white arrow points transversus abdominis muscle)

the intrathoracic pressure [1]. We postulate that repeated damage during cough attacks probably led to an abdominal wall hematoma aggravated by the antiaggregant and anticoagulant medications. The powerful contractions of the abdominal muscles may have caused the bleeding from the anastomoses between lower intercostal, lumbar and ascending branch of deep circumflex iliac artery. Varol et al. [2] report a similar abdominal wall hematoma case. In this case report, a rectus sheath hematoma, due to severe cough, occurred in a patient using oral anticoagulant therapy for atrial fibrillation. In severely coughing patients, sudden abdominal pain together with an abdominal painful mass, must alert physicians about the diagnosis of abdominal wall hematoma, especially in patients who are under anticoagulant and antiaggregant therapy.

Conflict of interest None.

\section{References}

1. Chang AB (2006) The physiology of cough. Paediatr Respir Rev $7(1): 2-8$

2. Varol E, Ozaydin M (2007) Rectus sheath hematoma due to cough attacks in an elderly patient on oral anticoagulant therapy. Anadolu Kardiyol Derg 7(2):235-236 